\title{
Coğrafik Bilgi Sistemleri İçin Mekânsal Etkileşim Analizi ile Adresi Bilgi Sistemi
}

\author{
Murat Taşyürek $^{1^{*}}$, Nuh Azgınoğlu ${ }^{2}$ \\ 1* Kayseri Üniversitesi, Mühendislik Mimarlık ve Tasarım Fakültesi, Bilgisayar Mühendisliği Bölümü, Kayseri, Türkiye, (ORCID: 0000-0001-5623-8577), \\ murattasyurek@kayseri.edu.tr \\ ${ }^{2}$ Kayseri Üniversitesi, Mühendislik Mimarlık ve Tasarım Fakültesi, Bilgisayar Mühendisliği Bölümü, Kayseri, Türkiye, (ORCID: 0000-0002-4074-7366), \\ nuhazginoglu@kayseri.edu.tr
}

(Uluslararası Araştırma-Geliştirme ve Tasarım Konferansı - 15-18 Aralık 2021)

(DOI: 10.31590/ejosat.1037582)

ATIF/REFERENCE: Taşyürek, M. \& Azgınoğlu, N. (2021). Coğrafi Bilgi Sistemleri İçin Mekânsal Etkileleşim Analizi ile Adres Bilgi Sistemi. Avrupa Bilim ve Teknoloji Dergisi, (32), 451-456.

$\ddot{O} z$

Adres Bilgi Sistemleri (ABS), coğrafi varlıkların özel amaçlı olmak üzere toplanması ve düzenli olarak depolanması amacıyla kullanılan Coğrafi Bilgi Sistemleri (CBS) için oldukça önemli bir bileşendir. Bu sistem içerisinde saklanan adreslerin doğruluğu ve tutarlığı sağlık, iletişim, güvenlik, posta ve kargo işlemleri, eğitim ve bunlarla birlikte birçok sosyal hizmetin sağlıklı bir şekilde yürütülebilmesi için kritik öneme sahiptir. İdeal bir ABS oluşturulması ve sorunsuz bir hizmet sunulması için CBS adres mimari tasarımının hem teorik hem de pratik açıdan mantıkl, tutarlı, etkin ve verimli bir şekilde yapılması gerekmektedir. Bu çalışmada adres bilgi sistemi mimari tasarımı için klasik ilişkisel veri tabanı tasarımı yerine mekansal etkileşim yöntemi önerilmiştir. Önerilen yöntemin klasik ilişkisel yönteme kıyasen daha başarılı olduğu ve klasik yöntemde ortaya çıkan problemlerin ortadan kaldırılmasında kararlı bir yapı ortaya sunduğu görülmüştür. Çalışmada kullanılan veriler Kayseri Büyükşehir Belediyesi'ne ait olup gerçek ve özgün verilerdir. Çalışma bir gerçek dünya problemine çözüm olması hasebiyle önemlidir.

\section{Address Information System with Spatial Interaction Analysis for Geographic Information Systems}

\begin{abstract}
Address Information Systems (AIS) is an essential component for Geographic Information Systems (GIS), which is used for the collection and regular storage of geographical assets for particular purposes. The accuracy and consistency of the addresses stored in this system are critical for health, communication, security, postal and cargo operations, education, and many social services to be carried out healthily. To generate an ideal (AIS) and provide a trouble-free service, the GIS address architectural design should be done logically, consistently, effectively, and efficiently, both theoretically and practically. This study proposes a spatial interaction method instead of a classical relational database design for addressing information system architectural design. It has been seen that the proposed method is more successful than the classical relational method and offers a stable structure in eliminating the problems that arise in the classical approach. The data used in the study belong to Kayseri Metropolitan Municipality and are genuine and original data. The study is critical because it is a solution to a real-world problem.
\end{abstract}

Keywords: Geographical Information System, Address Information System, Spatial Interaction.

* Sorumlu Yazar: murattasyurek@kayseri.edu.tr 


\section{Giriş}

Coğrafi Bilgi Sistemlerinin en önemli bileşeni olan adres bilgi sistemleri insanlara verilen birçok hizmetin aksamadan sürdürülebilmesi için oldukça önem arz etmektedir (Yomralıoğlu, 1994; Chang, 2016; Zhu ve ark., 2018; Öztürkçü, 2020; Adimalla ve ark., 2020; Taşyürek, 2021). Bu sistemlerde tutulan verilerin doğru, tutarlı ve güncel olması güvenlik, sağlı, iletişim, kurye ve posta hizmetleri gibi birçok farklı hizmet alanının sorunsuz işlemesini sağlamaktadır. Aksi durumda ise insanlar zaman kaybı, gözden kaçmalar, aksaklık vs. gibi istenmedik durumlarla karş1 karşıya kalmaktadır. Bu durum ise başta yerel yönetimler olmak üzere hem devletin kurumları için hem de vatandaşlar için olumsuz bir durum olarak karşımıza çıkmaktadır (Yıldırım, 2002). Dolayisıyla Adres bilgi sistemi, Kent Bilgi Sistemi, CBS (Tecim, 2008) gibi sistemlerde tutulan bilgilerin tutarlılığı ve standartlaştırılması son yıllarda tartışılmakta, yeni yöntemler önerilmekte ve farklı yaklaşımlar geliştirilmektedir (Yıldız, 2010; Ekinci 2010; Enönü, 2020, Morova, 2011; Ünal, 2006).

$\mathrm{Bu}$ kapsamda Türkiye Cumhuriyeti devleti tarafindan adreslerin merkezi bir veri tabanından çekilmesi, tekrarlı verilerin olmaması ve adres sisteminin belirli bir satandart çerçevesinde oluşturulması gibi amaçlarla Ulusal Adres Veri Tabanı (UAVT) oluşturulmasına karar verilmiştir. Birçok yerel yönetim bu sisteme dahil olmayla ilgili planlama yapmakta, projeler gerçekleştirmektedir (Yıldırım, 2002; Yıldırım, 2020; Aydınoğlu 2007; Aydınoğlu, 2010). Ünal (2006), adrese dayalı nüfus kayıt sistemlerinin kamu kurumlarınca kullanımı hususunda Denizli örneğini tartışmıştır. Enönü'nün (2020) yaptığı tez çalışmasında kentsel yönetimlerde altyapı yönetim bilgi sisteminin oluşturulmasına dair İstanbul için örnek bir çalıştırma gerçekleştirilmiştir. İlgili bilgi sisteminin önemli bir parçası da adres altyapısıdır. Morova ve arkadaşlarının (2011) çalışmasında Isparta kent merkezinin bir bölümü için web tabanlı adres bilgi sistemi uygulaması gerçekleştirilmiştir. Ekinci ve arkadaşlarının çalışmasında (2011) ise İstanbul'un Beykoz İlçesi için kent bilgi sistemi uygulaması anlatılmıştır. Yıldırım ve arkadaşları ise (2002) Kocaeli İli Pelitli İlçesi için bir adres bilgi sistemi uygulaması geliştirmişlerdir.

$\mathrm{Bu}$ çalışmada Kayseri Büyükşehir Belediyesi’nin (KBS) UAVT mimari tasarımının CBS'yle ortak çalışabilmesi amacıyla gerçekleştirilen klasik yöntem olan ilişkisel veri tabanı yöntemi ile önerdiğimiz yaklaşım olan mekânsal etkileşim yöntemi karşılaştırılmıştır. Önerilen yaklaşımın daha başarılı olduğu sonuçlarla ortaya konulmuştur.

Makalede akış şu şekilde olacaktır; öncelikle yöntem bölümünde problem tanımı ve çözüm önerisi verilmiştir. Ardından klasik ilişkisel yöntem ile önerilen mekânsal etkileşim yönteminin çözümü sunulmuştur. Sonuç ve tartışma kısmında iki yöntem için de elde edilen sonuçlar verilmiş ve genel değerlendirme yapılarak neticelendirilmiştir.

\section{Materyal ve Metot}

\subsection{Problem Tanımı ve Çözüm Önerisi}

KBB UAVT mimari tasarımının CBS'ye entegre edilmesi esnasında ilk olarak klasik veritabanı tasarım süreçlerinden olan ilişkisel veri tabanı yöntemi uygulanmış ve böylelikle UAVT bileşenlerinin güncelliğinin sağlanması amaçlanmıştır. Ancak geliştirme esnasında ilişsisel veritabanı yönteminin birden fazla ilçe ve mahalle sınırları içerisinde bulunan birimlerin mimari tasarımında sistemin adres entegrasyonlarının yapılamadığ görülmüştür. Çözüm olarak mekânsal etkileşim yöntemi ile UAVT mimari tasarımının oluşturulması önerilmiş ve böylelikle UAVT adres entegrasyon işlemleri yapılabilmiştir. Çalışma kapsamında KBB'ye ait mekânsal veriler kullanılırken, veri tabanı alt yapısı olarak ise Oracle kullanılmıştır.

\section{1. İlişkisel Veri Tabanı Yöntemi Çözümü}

Çalışma kapsamında ilk olarak kullanılan ilişkisel veri tabanı yöntemi için veri tabanı çözümü Tablo 1'de verilmiştir. Buna göre her adres için ilçe, bucak, köy, mahalle, CSBM (cadde, sokak, bulvar, küme evler), dış kapı ve bina bilgisi olmak üzere toplam yedi tabloda veriler tutulmaktadır. Tabloların birincil ve ikincil anahtarları ile diğer alan bilgileri Tablo-1'de görülmektedir.

$\mathrm{Bu}$ yöntemde tablolar birbirine ilişkisel olarak bağlıdır ve teorik olarak her şey yolunda gibi görünse de birden fazla ilçe sınırı ve doğal olarak da birden fazla mahalle sınırına değen adres alt yapılarının oluşturulması sorun teşkil etmektedir. Bu sorunun üstesinden gelmek için öncelikle uygulama aşamasında kayıtlar "duplicate" edilerek (çiftleme, tekrarlama) çözüm üretilmek istenmiştir. Fakat bu durumda da farklı ilçelerin kayıtları birbirine işlenebilmekte, uygulanmaya çalışılan çözüm farklı sorunlara yol açmaktadır. UAVT Adres alt yapısı ilişkilendirmesi Şekil-1'de verilmiştir.

Tablo 1. Illişkisel Veri Tabanı Tablo ve Alan Bilgileri.

\begin{tabular}{l|l|l|l|l}
\hline Tablo İsmi & Açıklama & $\begin{array}{l}\text { Birincil } \\
\text { Anahtar }\end{array}$ & İkincil Anahtar & Diğer Alanlar \\
\hline UAVTIlce & İçe Bilgisi & IlceUavtKod & - & Adi / Geometri \\
\hline UAVTBucak & BucakBilgisi & Bucak & IlceUavtKod & Adi / Geometri \\
\hline UAVTKoy & Köy Bilgisi & KoyUavtKod & BucakUavtKod & Adi / Geometri \\
\hline UAVTMahalle & Mahalle Bilgisi & MahalleUavtKod & KoyUavtKod & Adi / Geometri \\
\hline UAVTCSBM & Cadde, Sokak, Bulvar, Küme Evler Bilgisi & CsbmUavtKod & MahalleUavtKod & Adi / Geometri \\
\hline DisKapiNumarasi & Dış Kapı No. & DisKapiUavtKod & CsbmUavtKod & Adi/Geometri \\
\hline UAVTBina & Bina Bilgisi & BinaUavtKod & DisKapiUavtKod & Adi/Geometri \\
\hline
\end{tabular}




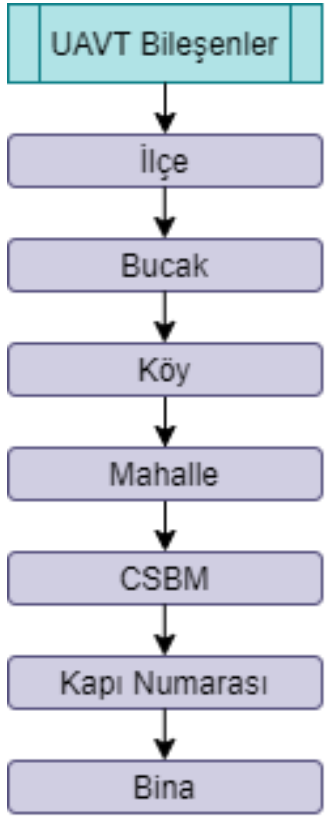

Şekil 1. UAVT Adres Alt Yapısı İlişkilendirmeleri.

\subsection{Mekânsal Etkileşim Yöntemi Çözümü}

UAVT mimari tasarımın oluşturulmasında yukarıda bahsettiğimiz sorunları ortadan kaldırmak ve entegrasyon işlemlerinin başarılı bir şekilde tamamlanmasını sağlamak amacıyla mekânsal etkileşim yöntemi önerilmiştir. Bu yöntemde adres bileşenleri arasındaki ilişkiler mekânsal etkileşim yöntemi ile belirlenmekte ve ilişkiler ona göre işlenmektedir. Birden fazla ilçe sınırı ve mahalle sınırına değen adresler değdiği noktalardan bölünerek yeni kayıtlar oluşturulmaktadır. Bu bölünme işleminde ilişkiler mekânsal etkileşim yöntemi ile otomatik olarak belirlendiği için herhangi bir sorun veya gözden kaçma durumu oluşmamaktadır. Kullanılan mekânsal etkileşim yönteminin nasıl kurgulandığına dair bilgiler aşağıda verilmiştir.

Oracle SDO_Contains mekânsal operatör fonksiyonu bir geometrinin diğer geometriyi içerip içermediğinin bilgisini verir. Bucak için bakacak olursak, bucak ilçe sınırları içerisindedir. Şekil-2'deki sorgu için P_Geometri parametresi bucak sınırını ifade etmektedir.

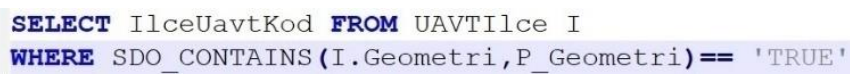

Şekil 2. Bucak İçin Mekânsal Sorgu.

Şekil-3’teki sorguda P_Geometri parametresi köy sınırını ifade etmektedir.

SELECT BucakUavtKod FROM UAVTBucak B WHERE SDO_CONTAINS (B.Geometri,P_Geometri) == 'TRUE'

Şekil 3. Köy İ̧̧in Mekânsal Sorgu.
Şekil-4'teki sorguda P_Geometri parametresi mahalle sinırını ifade etmektedir.

SELECT KOYUavtKod FROM UAVTKOY K WHERE SDO CONTAINS (K.Geometri,P Geometri)== 'TRUE'

Şekil 4. Mahalle İ̧̧in Mekânsal Sorgu.

Şekil-5'teki sorguda P_Geometri parametresi CSBM çizgisini ifade etmektedir.

SELECT MahalleUavtKod FRoM UAVTMahalle M WHERE SDO CONTAINS (M.Geometri,P Geometri)== 'TRUE'

Şekil 5. CSBM İçin Mekânsal Sorgu.

Şekil-6'daki sorguda P Geometri parametresi dış kapı numarası noktasını ifade etmektedir. SDO_TOUCH mekânsal operatör fonksiyonu bir geometrinin diğer geometriye değip değmediğinin bilgisini verir.

\section{SELECT CsbmUavtKod FROM UAVTCSBM C WHERE SDO TOUCH (C.Geometri,P Geometri)== 'TRUE'}

Şekil 6. Dış Kapı Çizgisi İçin Mekânsal Sorgu.

Şekil-7'deki sorguda P_Geometri parametresi bina sınırını ifade etmektedir. SDO_ANYINTERACT mekânsal operatör fonksiyonu iki geometri arasında herhangi bir etkileşim olup olmadığının bilgisi verir.

SELECT DisKapiUavtKod FROM DisKapiNumarasi D WHERE SDO_ANYINTERACT (D.Geometri,P_Geometri)== 'TRUE'

Şekil 7. Bina Sinırı İçin Mekânsal Sorgu.

\section{Deneysel Sonuçlar ve Tartışma}

Bu çalışmada KBB'den alınan Oracle ilişkisel veritabanında depolanan mekânsal veriler kullanılmıştır. KBB veritabanı tablosunda 574.274 adet kayıt bulunmaktadır ve deneysel çalışmalar bu gerçek verilerin tamamının kullanılmasıyla gerçekleştirilmiştir. Bu çalışmada yapılan deneyler 16 GB Ram, Intel Xenon Gold 5118 CPU $2.30 \mathrm{GHz}$ (4 Çekirdek), 600 GB SSD (Solid State Drive) disk özellikleri ve Windows Server 2016 işletim sistemine sahip sunucu üzerinde gerçekleştirilmiştir.

KBB'ye ait ilçe bazında UAVT adreslerinin genel bilgisi ve eşleştirme oranları hakkındaki deneysel sonuçlar Tablo-2'de verilmiştir. Elde edilen sonuçlara göre Melikgazi, Kocasinan, Talas, İncesu ve Hacılar ilçelerinde UAVT'de bulunan adreslerin mekânsal karșıllığı tam olarak (\%100) bulunmaktadır. Tablodaki nüfus sütunu incelendiğinde en fazla nüfusun bu bölgede olduğu görülmektedir. 
Tablo 2. Illçe Bilgileri ve Karşılaştırmalı Eşleștirme Oranları.

\begin{tabular}{l|l|l|l|l|l}
\hline İlçe İsmi & Alan $(\mathbf{k m 2})$ & Nüfus* & Mahalle Sayısı & $\begin{array}{l}\text { İlişkisel Veri } \\
\text { Tabanı Yöntemi }\end{array}$ & $\begin{array}{l}\text { Mekânsal } \\
\text { Etkileşim Yöntemi }\end{array}$ \\
\hline AKKIŞLA & 414.76 & 5999 & 15 & 81 & 81 \\
\hline BÜNYAN & 1220.66 & 30113 & 46 & 82 & 85 \\
\hline DEVELI & 1912.14 & 66250 & 77 & 79 & 83 \\
\hline FELAHIYE & 442.85 & 5569 & 17 & 75 & 75 \\
\hline HACILAR & 164.70 & 12443 & 12 & 92 & 100 \\
\hline INCESU & 807.94 & 28567 & 30 & 93 & 100 \\
\hline KOCASINAN & 1556.04 & 400726 & 93 & 91 & 100 \\
\hline MELIKGAZI & 599.13 & 582055 & 58 & 90 & 100 \\
\hline ÖZVATAN & 236.97 & 3891 & 13 & 80 & 80 \\
\hline PINARBAŞI & 3415.18 & 22900 & 122 & 77 & 79 \\
\hline SARIOĞLAN & 703.40 & 14107 & 27 & 75 & 75 \\
\hline SARIZ & 1203.99 & 9537 & 44 & 65 & 65 \\
\hline TALAS & 445.13 & 165127 & 30 & 95 & 100 \\
\hline TOMARZA & 1392.97 & 22028 & 54 & 80 & 81 \\
\hline YAHYALI & 1798.40 & 36208 & 41 & 92 & 92 \\
\hline YEŞILHISAR & 885.76 & 15935 & 35 & 95 & 1391 \\
\hline TOPLAM & 17200.02 & 1421455 & 714 & 1342 & \\
\hline
\end{tabular}

*2020 TÜİK verilerine göre

Nüfus bazında her iki yöntemin başarı oranı Şekil-8'de verilmiştir. Şekil 8'de sunulan grafikte $\mathrm{x}$ ekseni ilçeleri, y ekseni ise nüfus miktarını temsil etmektedir. Hem Tablo-2 hem de Şekil8 dikkate alındığında görülmektedir ki, önerilen mekânsal etkileşim yöntemi klasik ilişkisel yönteme göre daha başarılı sonuçlar ortaya koymuştur.
Şekil 8'de sunuldan sonuçlar dikkatlice incelendiğinde yöntemlerin sonuçları birbirine yakın gibi gözüksede toplam rakam olarak iki yöntem arasında yaklaşı olarak 110.000 adet farkı bulunmaktadır. Önerilen mekânsal etkileşim tabanlı yöntem klasik ilişkisel veritabanı yönetim sistemine göre nüfus bazında yaklaşık olarak 110.000 adet veriyi daha fazla eşleştirdiğinden dolayı çok daha başarı adres eşleştirme işlemi gerçekleştirmiştir.

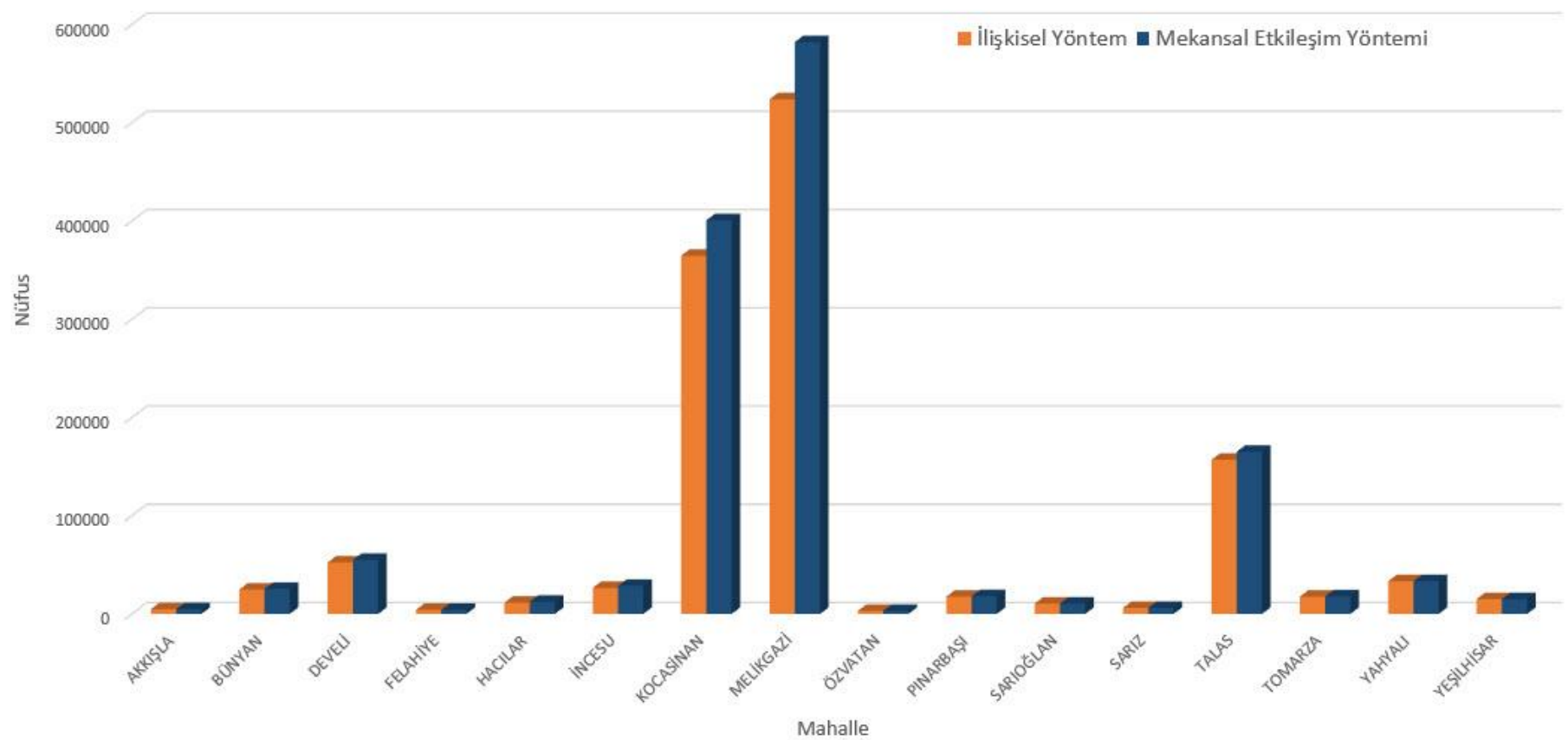

Şekil 8. Yöntemlerin Nüfus Bazında Başarım Oranları 
Yöntemlerin başarımları karşılaştırmak için diğer bir önemli kriter ise yöntemlerin çalışma süresidir. İlçe bazında yöntemlerin adres eşleştirme işlemindeki çalışma süreleri mili saniye cinsinden incelenmiş ve Şekil 9'da sunulmuştur. Şekil 9'da sunulan yöntemlerin çalışma süreleri incelendiğinde önerilen yaklaşım klasik yaklaşıma göre daha az sürede eşleştirme işlemini gerçekleştiğinden dolayı daha iyi performans göstermiş̧ir. Önerilen yöntemde mekânsal etkileşim için ekstra sorgulama işlemi harcamasına rağmen daha az veri üzerinde işlem yaptığından dolayı klasik ilişkisel veritabanı yöntemi sistemine göre daha hızlı sürede eşleştirme işlemini gerçekleştirmiş̧tir.

Önerilen mekânsal etkileşim tabanlı yöntem KBB tarafından aktif olarak kullanılmaktadır. Şekil 10 'da KBB coğrafi bilgi sistemlerinde mekânsal etkileşim yöntemi ile oluşturan adres sistemi sunulmuştur.

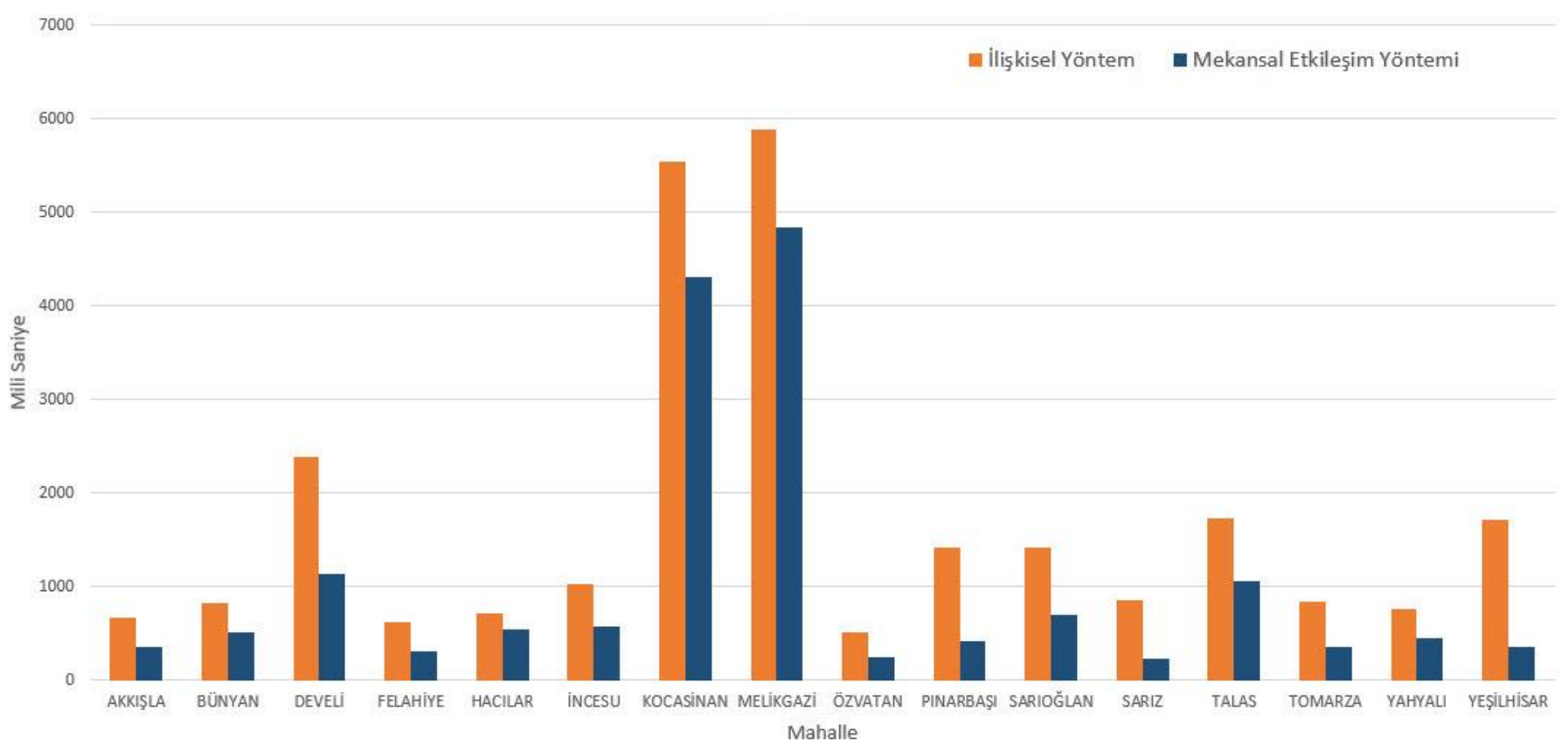

Şekil 9. Yöntemlerin Güncelleme Sürelerinde Başarım Oranları

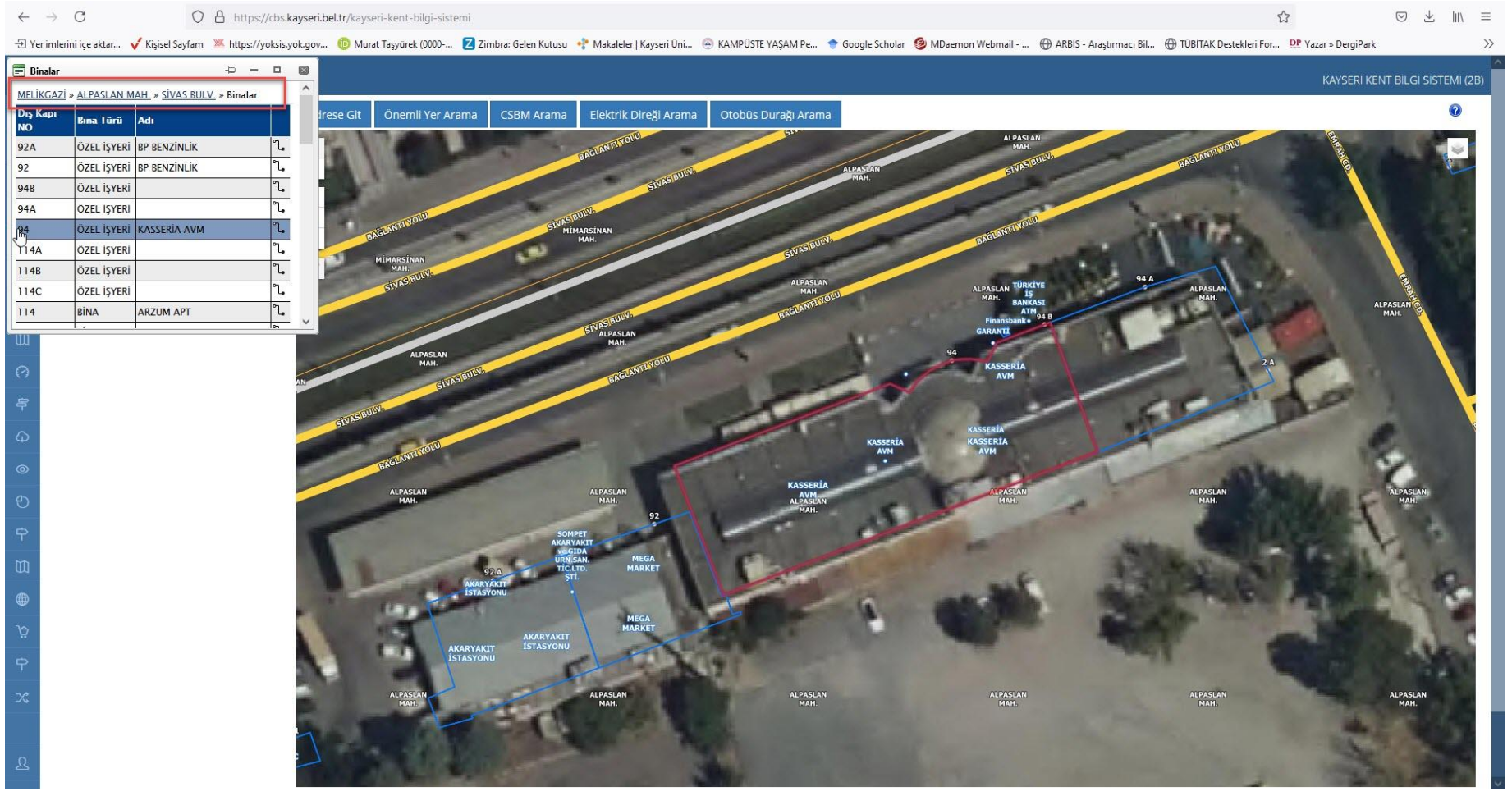

Şekil 10. KBB Mekânsal Adres Sistemi. 


\section{Sonuç}

UAVT adres bileşenlerinin oluşturulması ve güncel tutulması birçok sistemi etkilediğinden dolayı çok önemlidir. Bu çalışmada, UAVT adres bileşenlerinin entegrasyonu ve güncelliği sağlamak için mekânsal etkileşim tabanlı bir yöntem önerilmiştir. Deneysel değerlendirmeler KBB'den alınan gerçek veriler üzerinde gerkçekleştirilmiştir. Deneysel değerlendirmelerde önerilen yöntemin klasik ilişkisel veritabanı yöntemine göre adres eşletirme işleminde daha başarılı ve daha hızlı sürede eşleştirme yaptı̆ğ görülmüştür.

\section{Teşekkür}

Destek ve katkılarından dolayı Kayseri Büyükşehir Belediyesi’ne teşekkür ederiz.

\section{Kaynakça}

Adimalla, N., \& Taloor, A. K. (2020). Hydrogeochemical investigation of groundwater quality in the hard rock terrain of South India using Geographic Information System (GIS) and groundwater quality index (GWQI) techniques. Groundwater for Sustainable Development, $10,100288$.

Aydınoğlu, A. Ç., Yıldırım, V., \& Özendi, M. (2007). Ulusal Tabanlı Adres Bilgi Sistemi İçin İdari Birim Yapısının Konumsal Modellenmesi. TMMOB HKMO, 11.

Aydınoğlu, A. Ç. (2010). Geo-data management issues for urban land administration in Turkey.

Chang, K. T. (2016). Geographic information system. International Encyclopedia of Geography: People, the Earth, Environment and Technology: People, the Earth, Environment and Technology, 1-9.

Ekinci, B., \& Kavzoğlu, T. (2010). Beykoz İlçesi Kent Bilgi Sistemi.

Enönü, R. (2020). Kentsel yönetimlerde altyapı yönetim bilgi sisteminin oluşturulması: İstanbul Büyükşehir Belediyesi örneği (Yüksek Lisans Tezi, İbn Haldun Üniversitesi, Lisansüstü Eğitim Enstitüsü).

Morova, N. (2011). Web Tabanlı Adres Bilgi Sistemi Uygulaması: Isparta Kent Merkezi Örneği Y. Engineering Sciences, 6(2), 556-572.

Öztürkçü, T., \& Leyla, S. U. R. İ. (2020). Adres Bilgi Sistemlerinin Oluşturulması. İstanbul Ticaret Üniversitesi Teknoloji ve Uygulamalı Bilimler Dergisi, 2(2), 25-34.

Taşyürek, M. (2021). Mekânsal Verilerin S1klıkla Güncellendiği Coğrafi Bilgi Sistemleri Arama İşleminde Denormalizasyon Yöntemi. Avrupa Bilim ve Teknoloji Dergisi, (24), 18-23.

Tecim, V. (2008). Coğrafi bilgi sistemleri: Harita tabanlı bilgi yönetimi. Vahap Tecim.

Türk, T. (2008). Adres Kayit Sistemi ile Kent Bilgi Sistemlerinin Bütünleştirilmesi. Jeodezi ve Jeoinformasyon Dergisi, (99), 13-22.

Ünal, M. (2016). Adrese dayalı nüfus kayıt sisteminin kamu kurum ve kuruluşlarınca kullanımı: Denizli örneği.

Yıldırım, V., \& Yomraloğlu, T., (2002). Adres Bilgi Sistemi Uygulaması: Pelitli Belediyesi Örneği. İller ve Belediyeler Dergisi, vol.1, no.1, 25-32.
Yıldırım, V., \& Yomralığlu, T., (2002). Kent Bilgi Sistemlerinde Numaratajin Önemi: Pelitli Belediyesi Uygulaması.

Zhu, J., Wright, G., Wang, J., \& Wang, X. (2018). A critical review of the integration of geographic information system and building information modelling at the data level. ISPRS International Journal of Geo-Information, 7(2), 66. 